\title{
Transformación del área urbana de Paipa (Boyacá), 1950 2010. Análisis geohistórico
}

Transformation of the urban area of Paipa (Boyacá) 1950 2010. Geohistorical analysis

Wilson Hernando Rojas Espinel ${ }^{1}$

\section{Resumen}

Esta investigación aborda el proceso de transformación del área urbana de Paipa, departamento de Boyacá, Colombia, durante el periodo que va desde la segunda mitad del siglo XX hasta la primera década del XXI. El marco teórico se sustenta en la geografía histórica, en la geografía urbana y la geografía radical. Se identifican y se caracterizan las diferentes etapas del crecimiento urbano, teniendo en cuenta los datos socio-económicos, culturales, censos de población y fotografías aéreas del Instituto Geográfico Agustín Codazzi IGAC, para ver el incremento de la expansión física de la ciudad. La metodología utilizada es descriptiva y explicativa, enmarcada en la investigación cualitativa. Los resultados del trabajo muestran las tendencias de crecimiento del área urbana, en las que se establecen tres etapas en el crecimiento con características específicas que aportan a la comprensión de las dinámicas socio-espaciales; en suma, se genera información que puede tener aplicaciones prácticas en actividades conjuntas de la administración y la comunidad.

Palabras clave: Crecimiento urbano, expansión física, geografía histórica, geografía urbana, Paipa, población, transformación espacial.

1 Docente Secretaria de Educación Distrital de Bogotá. Bogotá D.C.- Colombia. wheroes33@gmail.com 


\section{Abstract}

This paper addresses the process of transformation of the urban area of Paipa, department of Boyacá, Colombia, during the second half of the $20^{\text {th }}$ century and the first decade of $21^{\text {st }}$ century. The theoretical framework is supported by the historical geography, urban geography and radical geography. The different stages of urban growth are identified and characterized, taking into account socio-economic, cultural data, population censuses and aerial photographs of the IGAC, to see the increase in the physical expansion of the city. The methodology used is descriptive and explanatory and framed on qualitative research. The results of the study show the trends of urban growth, which establishes three stages with specific characteristics that contribute to the understanding of socio-spatial dynamics. In addition, the paper generates information which may have practical applications in administrative and community activities as a whole.

Key words: Historical geography, Paipa, physical expansion, spatial transformation, urban growth, urban geography. 


\section{Introducción}

La ciudad es un espacio dinámico, resultado de las interacciones que el hombre genera sobre el medio natural en todas las dimensiones de la vida. Sin duda, la actuación del hombre tiene efectos en el espacio, es decir, en la ciudad. De acuerdo con Chueca:

Una ciudad se puede estudiar desde infinitos ángulos. Desde la historia, desde la geografía, desde la economía, desde la política, desde la sociología, desde el arte y la arquitectura (...) Y no son éstos los únicos enfoques posibles, porque la ciudad, la más comprehensiva de las obras del hombre, como dijo Walt Whitman, lo reúne todo, y nada que se refiera al hombre le es ajeno. No debemos olvidar que en su interior anida la vida misma, hasta confundirnos y hacernos creer que son ellas las que viven y respiran $(2009$, p. 95$)$.

La geografía urbana latinoamericana surge desde las geografías regionales entre los decenios del sesenta y setenta del siglo XX. Fueron Humboldt y Eliseo Reclus quienes hicieron aportes significativos en el estudio de la evolución de las ciudades latinoamericanas. De acuerdo con Portes y Dore (1996), las tendencias urbanas de los países del Tercer Mundo tienen en común su inserción dependiente en la economía global como proveedores de materias primas, productos agrícolas de consumo y servicios turísticos. Los espacios son creados y recreados de acuerdo con las ventajas comparativas que se ten- gan y dependen de las dinámicas sociales propias del ser humano. El crecimiento espacial constituye la expresión física del aumento de la población y de la dinámica socioeconómica.

Según Harvey (1990), entender el espacio y el tiempo es importante, ya que afecta la forma en que se interpreta el mundo y se actúa en él; es decir que el tiempo y el espacio son elementos constitutivos de la historia; ello permite estudiar y analizar la dinámica de los hechos sociales para identificar el ritmo de los procesos de evolución y crecimiento urbano. Entonces, el objeto de estudiar la ciudad a partir de la dinámica urbana bajo la dimensión histórica, significa entender el espacio como el resultado de un proceso histórico y obra del hombre, y no como una realidad física ajena a la relación de los elementos que los enlaza (Moncayo, 1990).

Las ciudades son espacios cada vez más complejos, donde "... las relaciones económicas, políticas, y culturales, se organizan a partir de los centros urbanos, y los procesos de producción, distribución y gestión, modifican profundamente la estructura espacial y social de las ciudades..." (Borja, 1997, p. 138). Teniendo en cuenta que el espacio se concibe como una construcción social, es importante analizar los factores que determinan una configuración espacial y las características que configuran dicho espacio, así como los impactos que se generan sobre el mismo, pues la ciudad es uno de los espacios más cambiantes que existe. 
Para encontrar respuesta a las variaciones geohistóricas del proceso de las transformaciones espaciales de Paipa, se identificarán y analizarán los cambios en la configuración de la estructura urbana, lo que implica realizar lecturas de las dinámicas que han configurado el espacio urbano. Se pretende caracterizar el proceso de transformación espacial, para contribuir al análisis de la dinámica espacial del municipio de Paipa; para lograrlo, el problema de investigación se origina y se estructura con el siguiente interrogante general: ¿Cómo ha sido el proceso geohistórico de la transformación urbana de Paipa en el periodo 1950-2010?

Así mismo, se buscó responder a los siguientes interrogantes específicos: ¿cuáles han sido las etapas de la transformación espacial de Paipa y cuáles son las características de cada una de ellas?, ¿cuáles son los factores que han incidido en el crecimiento urbano de Paipa y cómo se caracterizan?, ¿cuál ha sido el papel jugado por la planeación territorial por medio de sus instrumentos como el Plan de Ordenamiento Territorial (POT) respecto de la ocupación del uso del suelo y el crecimiento urbano de Paipa?, y ¿cuál es el resultado final y el aporte de la investigación a la comprensión y análisis de la evolución del espacio geográfico en Paipa?

A continuación se describirá brevemente el área de estudio, posteriormente se definirá la metodología utilizada en el trabajo, se presentarán los resultados obtenidos y se generarán las conclusiones finales.

\section{2. Área de estudio}

Paipa se localiza en el departamento de Boyacá. Geográficamente, la cabecera municipal se encuentra a los $5^{\circ} 47^{\prime}$ de latitud norte y $73^{\circ} 06^{\prime}$ de longitud oeste. De acuerdo con el Plan de Ordenamiento Territorial de Paipa, esta población abarca una extensión de $306 \mathrm{Km}^{2}$ aproximadamente, dista de la capital de la República cerca de $184 \mathrm{Km}$ y está a 40 Km de Tunja, la capital departamental. Limita por el norte con el municipio de Gámbita, departamento de Santander, por el oriente con los municipios boyacenses de Tibasosa y Duitama; por el sur con Firavitoba y Tuta, y por el occidente con Sotaquirá y Tuta (Figura 1). Para el año 2005, de acuerdo con el censo del DANE, la población total de Paipa era de 27.766 habitantes, y según las proyecciones de la misma entidad, para el año 2011 hay en total 29.606 habitantes, de los cuales 17.612 corresponden al área urbana. Paipa tiene una extensión total de 30.592 ha, de las cuales 332 corresponden al área urbana y representan el 1,8\% de la extensión total. Paipa pertenece a la provincia de Tundama y forma parte del corredor industrial y turístico de Boyacá.

El área de estudio se caracteriza por la importancia que le atribuyen factores como su ubicación geográfica, pues está localizada sobre la autopista que comunica a la capital departamental, Tunja, con las ciudades de Duitama y Sogamoso, lo que la convierte en un paso obligado en este recorrido. Además, por su importancia en el sector turístico, producto del desarrollo y aprovechamiento de las aguas termominerales que potencian el sector de 
Figura 1. Localización de Paipa.

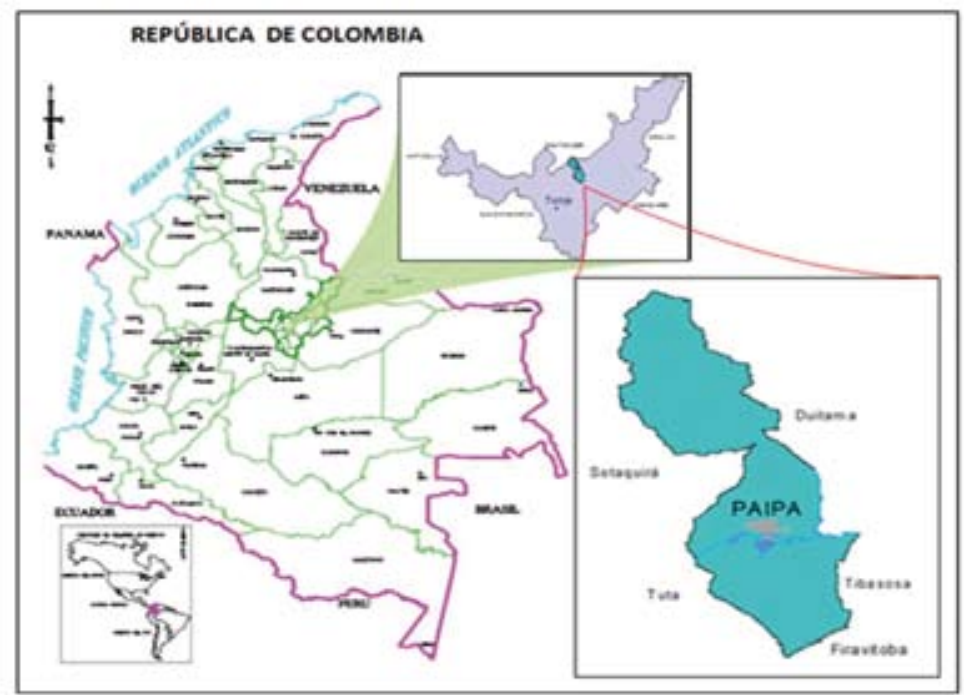

Fuente: Mapa base DANE. Localización departamental 2011. Adaptado por el autor.

servicios que se ofrece a los turistas, sin dejar de lado la belleza paisajística que tienen sus tierras y la tranquilidad que allí se encuentra, lo que hace de Paipa un lugar propicio para el descanso, la recreación y la vivienda.

\section{Antecedentes históricos de Paipa}

Paipa es una ciudad de estirpe indígena e hispánica que hizo parte de la nación chibcha, una de las grandes civilizaciones de América. Su conformación como centro poblado se remonta a la época precolombina cuando su población era natural de la región correspondiente al cacicazgo del Tundama. El primer contacto de los indios paipas se dio en 1537, cuando un grupo de colonizadores a la cabeza de Gonzalo Jiménez de Quesada pernoctó allí de paso hacia Sogamoso, en su intento de apropiarse de los tesoros del templo del Suamox (Camargo, 1997).

Desde el periodo de la Conquista, Paipa fue un lugar de estancia preferido por personajes notables de la administración española. "El 19 de febrero de 1602, el visitador Luis Enríquez ordena juntar los 1.184 indígenas nativos de las encomiendas de Bonza, Satiba y Paipa para formar un solo pueblo", de igual forma ordenó levantar la iglesia, y se hizo el trazo a mano alzada del plano de la distribución de lotes en el área urbana (Camargo, 1997). Paipa ha sido protagonista de importantes acontecimientos históricos: en 1781 , los paipanos participaron en la 
revuelta de los Comuneros, y en 1919 la población fue escenario de la batalla del Pantano de Vargas, al mando de Bolívar, que dio paso a la batalla del Puente de Boyacá.

\section{Metodología}

El trabajo de investigación es de carácter descriptivo y explicativo, enmarcado dentro de la investigación cualitativa. Se identifican y analizan los factores que han incidido en dicho proceso (Figura 2). Se caracteriza por ser una investigación documental, con énfasis en el análisis desde la geografía histórica y urbana, recurriendo a un proceso de revisión de fuentes primarias y secundarias. Como técnica de recolección de información primaria de la investigación está la observación directa como trabajo de campo, para verificar y evidenciar los cambios físicos del espacio de acuerdo con la información obtenida, además para constatar y analizar las características físicas de dicho proceso evolutivo con la toma de fotografías en campo. Se hacen entrevistas semiestructuradas a algunas personas adultas mayores que han vivido en la ciudad y han sido testigos del proceso evolutivo del espacio en el periodo estudiado; también se interroga a algunos turistas para obtener su percepción de Paipa como sitio turístico.

La técnica de recolección de información secundaria que hace parte del proceso de investigación es la documental, y las principales fuentes son las bibliográficas y documentales, datos estadísticos e históricos obtenidos de entidades y bibliotecas públicas y privadas del departamento de Boyacá y de Bogotá; fuentes cartográficas, relacionadas con planos, fotografías aéreas y mapas. Se analizan las fotografías aéreas del IGAC durante el periodo de estudio 1945-2010, para establecer las áreas de expansión y calcular el porcentaje de crecimiento físico del área urbana, el cual se hace mediante el uso de software ArGys.

El procedimiento consiste en hacer un procesamiento digital, escaneando las fotografías convirtiéndolas en imágenes de alta resolución, mejorando su calidad pictórica para seguir con el proceso de georreferenciación sobre el mapa base de Paipa que tiene escala 1:10.000; también se usa el perímetro urbano más reciente que corresponde al Plan de Ordenamiento Territorial vigente en Paipa. Se efectúan la edición y la disposición como capas temáticas identificadas topológicamente para el análisis espacial en cuanto a expansión urbana, determinando las medidas en hectáreas de las áreas que han crecido y que conforman las manchas urbanas nuevas en cada periodo de estudio.

Igualmente se tienen en cuenta los datos estadísticos del DANE sobre la población entre 1951 y 2005 , relacionando el incremento poblacional presentado con el crecimiento espacial del área urbana. Se hace un análisis socioeconómico y cultural al inicio del primer periodo para establecer la evolución de dichas caracteristicas poblacionales. La información proveniente de documentos 
Figura 2. Esquema de la metodología.

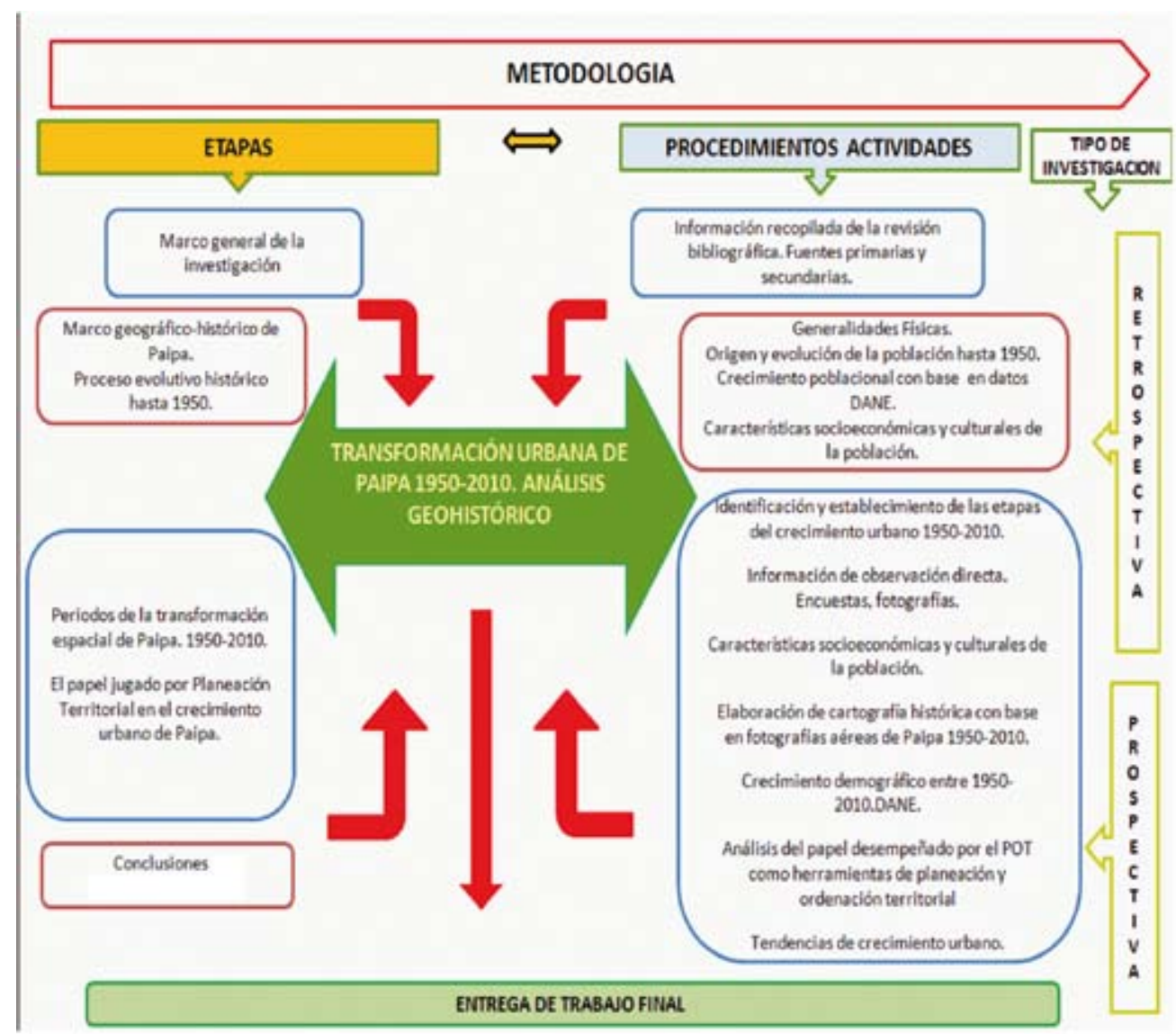

Fuente: elaboración del autor.

públicos, como los planes de ordenamiento territorial (POT), datos obtenidos en organismos estatales como el DANE en los censos de población de la segunda mitad del siglo XX y comienzos del XXI en nuestro país, es fundamental para ver la dinámica del crecimiento en Paipa en forma cuantitativa a través del tiempo y para comprender la evolución de expansión espacio-temporal. Así mismo, es importante la consulta de bibliografía sobre los ejes de la investigación, como la geografía urbana, la geografía histórica y la geografía radical, teniendo en cuenta investigaciones sobre Paipa desde diferentes disciplinas.

En términos generales, la metodología desarrolla una fase retrospectiva y una prospectiva.

En la primera fase, o retrospectiva, se indaga sobre los hechos ocurridos en el pasado. Aquí se definen algunos 
procesos claves en la configuración del espacio urbano, los cuales conducen a otros procesos que permiten explicar la transformación espacial de la estructura de Paipa. También se analizan las estructuras socioeconómica, demográfica, política y la forma de la configuración espacial urbana.

En la segunda fase, o prospectiva, se registra la información según la ocurrencia de los hechos o sucesos, teniendo en cuenta que la transformación espacial y el desarrollo local dependen de la realidad interna de cada territorio y de las orientaciones que se manifiestan en su entorno. Se pueden vislumbrar hacia el futuro formas y tendencias de expansión y crecimiento de la ciudad, para lo cual se debe considerar la funcionalidad del POT sobre el uso adecuado de los suelos, a fin de disminuir conflictos por mal uso de los mismos.

\section{Etapas de la transformación urbana de Paipa}

El aumento paulatino de la ocupación del suelo por construcciones y usos directamente relacionados con los asentamientos urbanos es uno de los efectos indiscutibles de los procesos de urbanización. La transformación espacial de un lugar se da por condiciones, variables y características particulares de cada uno. La expresión física del crecimiento espacial depende de factores como el aumento de la población en número de habitantes y de su dinámica socioeconómica. De acuerdo con Vinuesa (1991, p. 45), “El crecimiento del número de habitantes así como de las actividades sociales, políticas, económicas o comerciales de diferente tipo, exigen ampliaciones del espacio urbano existentes". En otras palabras, cualquier transformación espacial desarrolla eventuales procesos de cambio del suelo en los espacios construidos.

El crecimiento urbano de Paipa se ha originado en gran medida por el turismo y las actividades inherentes al mismo, como el comercio, y por los eventos socioculturales que allí se efectúan. Hay que anotar que estos procesos son favorecidos por el desarrollo de la infraestructura vial local y regional.

\section{Primer periodo: 1950-1970, inicio leve de expansión urbana}

Se identifica como una etapa en la cual se da un letargo en el crecimiento urbano, se presenta una ralentización en cuanto a la expansión física del espacio en comparación con los subsiguientes periodos de estudio. En este periodo, Paipa se caracteriza por ser un pequeño centro poblado cuyos rasgos socioeconómicos giran principalmente en torno al desarrollo de actividades agrícolas y pecuarias, base de la economía de sus gentes (Figura 3). En este lapso se establecen dos momentos, que se describen a continuación.

\section{Paipa 1950-1960}

En Boyacá era mayor en número la población rural que la urbana, característica agrícola que se ha mantenido por mucho tiempo. Por directrices nacionales, a par- 
tir de 1947, con la expedición de la Ley 88 , se establecen temas de planificación territorial para las ciudades y municipios, que debían fijar un plan para regular el desarrollo urbano, el cual se implanta sobre la década de los cincuenta como una herramienta esencial para el urbanismo y el desarrollo de las ciudades.

El crecimiento físico inicia su proceso sobre la vía principal que pasaba por el centro del poblado, aunque, en realidad, era un camino sin mayor importancia dadas las características de calle secundaria que tenía para la fecha. De acuerdo con las fotografías aéreas, el área urbana de Paipa hasta este periodo tenía aproximadamente una extensión de 13 ha. Con base en la relación multitemporal de fotografías aéreas de los años 1944 y de 1966, se puede determinar que el área urbana crece cuatro hectáreas en 22 años, pasando de trece en 1944 a ocupar 17 ha en 1966. Significa que en promedio cada diez años Paipa pudo ampliarse en dos hectáreas. En la década del 50 había crecido aproximadamente hasta $15 \mathrm{ha}$. La mancha física del área urbana era pequeña, por diferentes causas. Por un lado, el centro poblado se estableció inicialmente entre las márgenes de dos quebradas, el Rosal y el Valencí, las cuales sirvieron de barrera natural para limitar el crecimiento urbano de Paipa. Por otro lado, la vía principal, que conectaba a Paipa con Tunja y Sogamoso, cruzaba por la actual carrera 21 , cuyas características de vía secundaria en la región no estimulaban la urbanización.
Otra causa del débil crecimiento urbano fue el establecimiento de las gentes privilegiadas en el centro, quienes tenían rasgos criollos, y gozaban de poder y riqueza, y aunque eran muy pocos en número para la época, mantenían aún una hegemonía de clase. La zona se tornaba inaccesible para los estratos bajos que desde tiempos antiguos habían sido desplazados hacia la parte adyacente y rural, y se dedicaban a laborar en el campo para subsistir en los pequeños minifundios. Hasta el final del periodo predominó la construcción de viviendas a base de adobe o bahareque y con techos de paja, debido a las condiciones socioeconómicas poco favorables para acceder a otros materiales de construcción como la teja de barro; solamente accedían a viviendas más elaboradas quienes tenían los recursos económicos para hacerlo. Algunas de las viviendas del área urbana y las que rodeaban la plaza central tenían estas características de distinción y estilo y pertenecían a la gente de prestigio y reconocimiento social.

La industria en Paipa es incipiente en razón a la baja población urbana existente y su baja dinámica económica. La población total de Paipa, que para el mismo año corresponde al $1 \%$ del total departamental, comprende una población urbana que representa el $11 \%$, lo que significa que su población rural equivale al $89 \%$; población esta última dedicada a la agricultura y ganadería básicamente. 


\section{Paipa 1961-1970}

En la década del 60 se marcan algunos cambios importantes en la sociedad y el medio natural, ya que durante el gobierno de Rojas Pinilla (1953-1957) se habían formulado proyectos de infraestructura importantes a nivel regional que condujeron a generar transformaciones espaciales significativas. Por ejemplo, se estableció para Tunja la construcción de la avenida Oriental junto con la ampliación de la carretera Central del Norte que comunica a Tunja con Paipa, Duitama y Sogamoso, principales núcleos urbanos del departamento (Rincón, 2009). Con la construcción de la autopista Norte, en Paipa se fue desplazando de forma rápida al tren que había servido como medio de transporte hasta la década del cincuenta, pues con la autopista, las flotas redujeron a cuatro horas el tiempo de desplazamiento hacia Bogotá. La modernidad se fue abriendo paso con características capitalistas. Una de las consecuencias de la construcción de la autopista Norte para el área urbana de Paipa fue el impulso de actividades comerciales, puesto que este era un centro poblado intermedio entre Tunja, la capital, y las ciudades de Duitama y Sogamoso que se destacaban por generar actividades industriales y comerciales importantes para la época.

Las actividades industriales fueron impulsadas bajo el gobierno de Carlos Lleras Restrepo, entre 1966 y 1970, principalmente en las ciudades, fomentando así el desarrollo urbano. Sin embargo, en Paipa se inicia la construcción de una destacada obra del sector industrial, la termoeléctrica -ubicada sobre la auto- pista Norte, hacia la entrada del valle de Paipa-, junto con lagos artificiales para el funcionamiento de la termoeléctrica, y con ellos, el lago Sochagota, que para la época introduce belleza al paisaje natural y al mismo tiempo se convierte en escenario de actividades deportivas. Para este periodo, la actividad turística aún era incipiente por las pocas condiciones de infraestructura que limitaban el desarrollo de este sector dentro de la economía local.

Durante este tiempo, exactamente en el año 1966, el área urbana de Paipa presentó un aumento de su espacio en un $27 \%$, respecto al momento anterior. Hubo un crecimiento físico que pasó de 15 ha en la década del cincuenta, a 17 ha en la década del sesenta. Según el DANE, en 1970 Paipa contaba con 280 predios urbanos que formaban y habitaban 724 viviendas. El crecimiento físico es aislado pero significativo hacia el norte y el occidente, mientras que hacia el sur y el occidente se expande de forma débil. Aun con este crecimiento urbano, la urbanización no sobrepasa las barreras naturales establecidas, es decir, las quebradas el Rosal y el Valencí. Pero a finales de la década del sesenta, estas fueron intervenidas por el hombre quien las canalizó con el objetivo de poder transformar el espacio urbano en los periodos siguientes.

En 1969, año en el cual se erige el monumento a los Lanceros en el Pantano de Vargas, también en Paipa se levanta el monumento a Inocencio Chincá sobre la avenida Central del Norte, hecho que dio el nombre a la vía que atraviesa el 
área urbana del municipio. Otra obra de impacto para la época fue la prolongación de la vía "la sexta", denominada Juan José Rondón, que va desde el costado sur del área urbana en el centro de Paipa, sobre la actual calle 25 con el cruce en el ferrocarril, hasta las piscinas termales.

\section{Segundo periodo: 1971-1992, crecimiento urbano acelerado y consolidación del turismo}

El segundo periodo comprende los años 1971-1992. Durante este tiempo, el crecimiento del espacio urbano se caracteriza por un amplio y acelerado desarrollo sin un adecuado control en la planificación para la expansión territorial; las características socio-económicas siguen girando en torno a las actividades agropecuarias, sin embargo durante esta etapa se establecen elementos adicionales que jalonan más el crecimiento urbano, como el turismo y las actividades derivadas de él, entre ellas el comercio. Se generan así nuevas dinámicas en la población que tienen implicaciones tanto en el uso del suelo como en las actividades económicas y socioculturales.

Colombia cuenta con riquezas minerales incalculables, entre las que se destacan las aguas minerales y termominerales que están distribuidas principalmente en el área andina. En esta área sobresalen las aguas termominerales de Paipa que surgen de numerosas fuentes reconocidas por sus propiedades medicinales. Las termales de Paipa, junto con los sitios adecuados para la optimización de su disfrute, desarrollan y potencian dos sectores, por un lado, el turismo, la recreación y la salud, y por el otro, la industria de recuperación de sales. La estación del Ferrocarril del Nordeste y el aeropuerto propio se convierten en elementos que dan importancia a Paipa para su vocación turística, agrícola, industrial y ganadera. La infraestructura vial interna aumenta y de igual manera se mejoran las condiciones de las vías existentes, tanto en el departamento de Boyacá en general, como en Paipa. Implícitamente con el desarrollo vial se buscaba potenciar el desarrollo de Paipa como un centro turístico de características importantes para dinamizar las actividades socio-económicas locales y del departamento de Boyacá.

Según Zarate (1991), el acoplamiento de la ciudad y de las nacientes áreas urbanas dependerá así mismo del crecimiento de la malla vial, que determina el ritmo de la dinámica urbana, identificándose como un elemento articulador del territorio. Durante este periodo surgen en Paipa nuevos barrios urbanos que son dependientes política y administrativamente del centro del poblado. De acuerdo con lo anterior, la característica de urbanización compacta que se había mantenido hasta la década de los sesenta, fue cambiada con el desarrollo urbano por características propias de "ciudad difusa", en relación con la separación espacial (Rincón, 2009).

\section{Paipa 1971-1985}

El crecimiento urbano de Paipa se caracteriza por su amplia expansión hacia los 
costados norte, occidente y sur, con un moderado crecimiento hacia el costado oriental. El crecimiento urbano hasta el año 1985 corresponde a 58 ha, lo que significa que entre 1966 y 1985 hubo un incremento urbano de 35 ha. A partir de este periodo, el casco urbano pierde la uniformidad antigua de construcción, lo cual significa que la cuadrícula, que inicialmente se había concebido como guía para la construcción urbana quedó relegada en razón al rápido y descontrolado crecimiento. El contraste de las dos formas de construcción es evidente, ya que hacia el centro se mantuvo la homogeneidad mientras que los nuevos barrios carecen de este parámetro (Figura 3).

Hacia el norte y al noroccidente, el crecimiento se da en torno a la nueva autopista Norte, de forma no organizada; en esta área se crean los barrios Villa Vianey, los Rosales, Gaitán y San Miguel, que son ejemplos de la pérdida de la connotación de cuadrícula; hecho que se debe en parte a la topografía del terreno cuyo relieve está conformado por lomas con inclinación moderada. También se identifica un importante crecimiento urbano hacia la parte sur, destacado por el desarrollo de las piscinas termales y la construcción de algunos hoteles sobre la vía "sexta" que comunica el centro urbano con dichas piscinas ubicadas hacia el área rural adyacente al lago Sochagota. Iniciando la década del ochenta, de forma paralela a la vía se construye un corredor peatonal y ciclístico sobre el cual se edifican hospedajes, hoteles y establecimientos comerciales, y se crean los barrios Villa Panorama, Primero de Mayo y las Quin- tas. La vía férrea, que había sido una barrera histórica frente a la expansión urbana, fue sobrepasada. Paipa pasa de ser un centro poblado pequeño a destacarse como una ciudad intermedia ${ }^{2}$ por su expansión física y demográfica, y por la dinámica de sus actividades económicas y socio-culturales, que son reconocidas ampliamente en el ámbito local, regional y nacional, convirtiéndose en una de las cinco urbes en importancia del departamento de Boyacá.

Por la presión urbanística durante este periodo, las áreas adyacentes al río Chicamocha son convertidas en espacios de vivienda. Las construcciones de este tiempo se caracterizan por una arquitectura moderna que rompe y desdibuja la arquitectura tradicional que se había mantenido por cientos de años en la construcción. Entre dichas obras sobresale la construcción del hotel Zuhe y el edificio de la alcaldía municipal.

La elevada construcción del costado norte del área urbana, pues en los cerros que bordean dicho sector se han desarrollado barrios, ha exterminado el verde natural que estos mantenían. Dichos barrios no son constituidos de forma uniforme y como consecuencia, visualmente se asemejan a los barrios de invasión de ciudades como Tunja y Bogotá porque no tienen una armonía arquitectónica establecida. En Paipa predominan las

\footnotetext{
2 El concepto de "ciudad intermedia" o "ciudad media" es muy diverso. De acuerdo con Vilagrasa (1999), "EI Banco Mundial considera esta categoría hasta 1.000 .000 de habitantes". Mientras que según la Unión Europea, la determina la población que oscila entre los 50.000 y los 500.000 habitantes.
} 
características turísticas que impulsan su desarrollo urbano, económico, social y cultural atrayendo el interés de personas de la región y de extranjeros para establecerse en Paipa. En la década del setenta, alrededor del lago Sochagota se inicia el desarrollo de obras de infraestructura de recreación privada, así como también de industria hotelera cuya primera obra fue el hotel Termales o Colonial; además se construyen las cabañas el Recreo que han invadido el espacio natural de dicho lago.

\section{Paipa 1986-1992}

Con la promulgación de la Ley 9 de 1989, de reforma urbana, durante el gobierno del presidente Virgilio Barco, se buscó la implementación de mecanismos de gestión y control sobre el crecimiento y expansión de la ciudad. En esta ley se dio importancia a la formulación de planes parciales, al estudio de programas de vivienda, de planes de renovación urbana, así como a la regulación de las licencias de construcción con la finalidad de controlar el crecimiento urbano tanto de ciudades como de municipios.

En este momento histórico, la expansión urbana se caracterizó por ser un proceso lento pero con ritmo medianamente constante. El crecimiento urbano se dio principalmente hacia el costado oriental y noroccidental, así como el costado sur, aunque se desarrolló una pequeña mancha en el norte que viene a consolidar el urbanismo desde el centro hacia la autopista Norte. La expansión física del área urbana entre 1985 y 1992 corresponde a
10 ha, equivalentes a un $18 \%$ durante siete años.

La expansión urbana durante este periodo consolidó la conformación y el establecimiento de los barrios Gaitán, San Felipe y los Libertadores en el costado oriental del área urbana; mientras que hacia el costado sur, el crecimiento fue amplio en relación con la construcción y consolidación de los barrios Villa Panorama, y, en menor medida, de los barrios Primero de Mayo y las Quintas.

\section{Tercer periodo: 1993-2010, continuidad urbana y turística}

El tercer periodo corresponde a los años 1993-2010. En este tiempo se sigue presentando la expansión física del área urbana de Paipa, al igual que sigue creciendo su población; aunque dicho proceso no es tan acelerado como el identificado en el periodo anterior, sí mantiene un ritmo de crecimiento constante. Los renglones que priman en este lapso, como ejes articuladores de la economía, son las actividades terciarias que traslapan las actividades económicas primarias sin dejarlas de lado. El turismo continúa su desarrollo de forma más amplia y acentuada, gracias a la organización y estructuración del corredor turístico de Boyacá, conformado por Paipa y los pueblos de Tibasosa, Pantano de Vargas, Duitama e Iza.

Hacia 1995, tanto en Paipa como en el resto de las ciudades aledañas, y en general a nivel nacional, comienza una densificación urbana aguda debido a 
problemas de orden público que hace que Colombia pase de ser un país rural a ser un país más urbano. La población rural comienza a buscar refugio en poblaciones donde aparentemente este problema no las afecta o por lo menos no en la misma intensidad. Como respuesta a estos sucesos comienzan a generarse urbanizaciones de vivienda social y de auto-construcción, como la urbanización el Bosque hacia el costado nororiental.

\section{Paipa 1993-2003}

El crecimiento urbano en este momento se desarrolla hacia el norte, el noroccidente y el sur, en menor medida hacia el oriente. El área que se incrementa entre 1992 y 1997 es de 18 ha, correspondientes al $26 \%$. En 1997, el área urbana ocupa una extensión de 87 ha, mientras que en 1992 correspondía a 68 ha. Hacia el sur, la expansión física se da en torno a la ronda del río Chicamocha y sobre la vía turística que se extiende desde el área urbana de Paipa hacia las termales y los complejos recreacionales y hoteleros circundantes al lago Sochagota. Se construyen viviendas que consolidan y amplían los barrios el Bosque, Primero de Mayo y Villa Panorama. De igual forma, el crecimiento urbano hacia el noroccidente se da sobre la autopista Norte, con el barrio Sausalito, y hacia el norte con los barrios San Felipe y Pablo Solano. Para este periodo se ha perdido la uniformidad del trazado original del área urbana -cuadrícula- y las construcciones dan paso al surgimiento de barrios sin homogeneidad en su construcción (Figura 3).

\section{Paipa 2004-2010}

La expansión física en esta etapa permite consolidar a Paipa como una ciudad intermedia con carácter turístico y como uno de los cinco núcleos urbanos de Boyacá con mayor importancia después de Tunja, Duitama, Sogamoso y Chiquinquirá. La expansión física del área urbana se da en un $37 \%$. En el año 2004, la zona urbana es de 124 ha, mientras que en 1997 era de apenas 87 has. El crecimiento urbano en este periodo se caracteriza por extenderse hacia el sector norte, el sector nororiente sobre la autopista Norte, hacia el occidente y hacia el sur del área urbana. Este crecimiento fortalece los núcleos urbanos de los barrios iniciados en años anteriores, como el barrio Sausalito, San Felipe, Libertadores, San Miguel, Villa Panorama y Primero de Mayo. También surgen barrios nuevos como las Delicias, Fátima, Villa Jardín, la Pradera y Fátima (Figura 3). Para el año 2011, la población urbana de Paipa corresponde al $61 \%$ con 17.612 habitantes del total, mientras que la población rural representa el $39 \%$ con 11.994 habitantes (Tabla 1).

Tabla 1. Síntesis expansión física de Paipa

\begin{tabular}{|c|c|c|}
\hline $\begin{array}{c}\text { PERIODOS } \\
\text { ANÁLISIS }\end{array}$ & $\begin{array}{c}\text { ÁREA } \\
\text { (ha) }\end{array}$ & $\begin{array}{c}\text { TASA } \\
\text { VARIACIÓN (\%) }\end{array}$ \\
\hline 1945 & 14 & 0 \\
\hline 1966 & 17 & 28 \\
\hline 1985 & 58 & 236 \\
\hline 1992 & 69 & 18 \\
\hline 1997 & 87 & 26 \\
\hline 2004 & 124 & 43 \\
\hline
\end{tabular}

Fuente: Fotografías aéreas del IGAC, 1945-2004. 
Figura 3. Síntesis de los periodos de la expansión urbana de Paipa, 1947-2004.

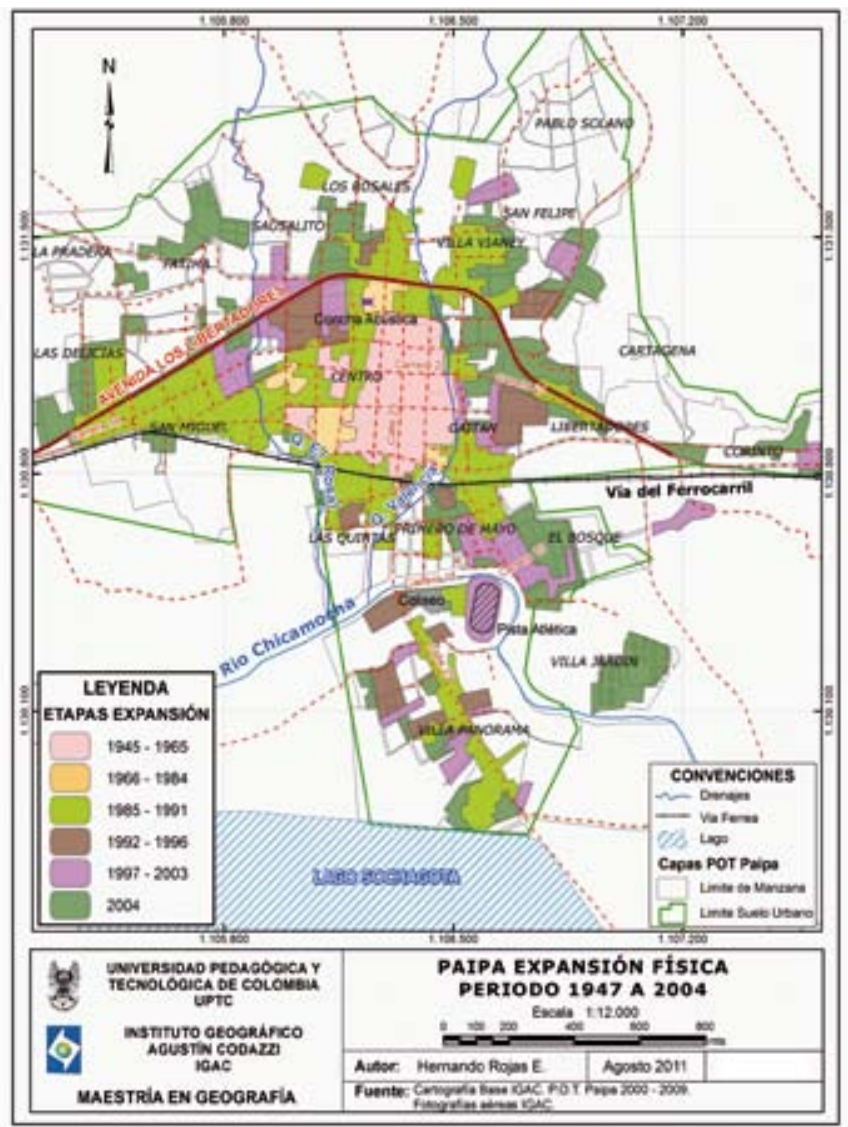

\section{Conclusiones}

Para finales del siglo XX y durante la primera década del siglo XXI, Paipa se consolidó como una ciudad intermedia debido al crecimiento físico y al aumento poblacional. En este municipio, el espacio ha sido el resultado de la construcción social pues su dinámica ha respondido a unas necesidades e intereses, entre los que se destacan: cubrir la demanda de ubicación y vivienda en el área urbana de los habitantes que por razones como el desplazamiento campo-ciudad y la búsqueda de una mejor calidad de vida y mejor educación para los jóvenes, etc., deciden trasladarse y establecerse de forma permanente en la ciudad.

Otras de las razones por las que el espacio de Paipa es una construcción social son las interrelaciones que se dan en esta población y, así mismo, la dinámica socioeconómica generada allí por la 
actividad turística y la vocación de Paipa como un lugar que ofrece multiplicidad de actividades recreativas, deportivas y culturales. Actividades que generan un dinamismo creciente desde mediados del siglo XX, que se manifiesta en la presencia de turistas que buscando un lugar para el descanso han establecido viviendas en esta ciudad, como lugar de segunda residencia, por las ventajas que allí se ofrecen; cabe destacar, la seguridad, la tranquilidad, la belleza paisajística, las piscinas termominerales y la calidad humana de los habitantes locales.

Teniendo en cuenta las tendencias de expansión física de la ciudad (producto de la observación de los mapas generados), de la dinámica poblacional, así como de las características socioeconómicas y de la lectura de las políticas nacionales y locales establecidas para la ordenación del territorial, se establecieron tres periodos de crecimiento del tejido urbano. Cada periodo se ha caracterizado por la expansión física, el aumento de la población y el cambio de las actividades económicas de los habitantes.

Un primer periodo inicial de leve de expansión urbana entre 1950-1970, en el que las características de urbanización mantienen un orden y homogeneidad como el establecido desde la Conquista, en el diseño y trazado urbano con la cuadrícula española.

Un segundo periodo, de crecimiento urbano acelerado y consolidación del turismo entre 1971 a 1992, caracterizado por un desarrollo urbano disperso y poco homogéneo en las construcciones, que lleva a la pérdida del principio de organización urbana dado por la cuadricula. También es notoria en esta etapa la influencia del turismo como una actividad que genera unas dinámicas socioeconómicas complejas. La población cambió sus actividades económicas de antaño basadas en la agricultura y la ganadería pasando a ser una ciudad de actividades económicas terciarias que ofrece productos y servicios de amplia gama a quienes la visitan gracias a sus atractivos turísticos.

En el tercer periodo, de continuidad urbana y turística entre 1993-2010, la expansión física y la actividad económica de carácter terciario siguen aumentando y caracteriza las dinámicas y las interrelaciones socio-espaciales que tienen lugar en la ciudad.

Podemos afirmar que las ciudades medianas se ven afectadas por factores externos que influyen en los aspectos internos, como en el caso de estudio. En la ciudad de Paipa se refleja la actividad comercial consecuencia del turismo que genera dinámicas socioeconómicas importantes.

Entre los factores que han incidido en la transformación del espacio y la dinámica expansionista en Paipa se destacan: por una parte, la influencia de las políticas desarrolladas por el gobierno nacional que buscan articular e insertar a las ciudades en la economía local y nacional promoviendo obras de infraestructura importantes, entre ellas las obras viales, como la construcción de la autopista 
Norte a mediados del siglo $\mathrm{XX}$, y la construcción en el siglo XXI de la doble calzada que interconecta a Bogotá, Tunja, Duitama y Sogamoso pasando necesariamente por Paipa. Lo anterior ha potenciado la actividad turística con base en la explotación de los recursos naturales con los que cuenta Paipa, como las aguas termominerales que tienen características físico-químicas extraordinarias y son de amplio reconocimiento a nivel local, regional, nacional e internacional.

Por otra parte, el crecimiento urbano también se ha originado por las actividades inherentes al turismo como el comercio y los servicios que año tras año han ido en aumento, así como por los eventos socioculturales que allí se desarrollan, sin duda alguna, para Paipa el turismo significa cultura y participación económica. El turismo genera unas dinámicas particulares en torno al comercio que deriva del mismo y a la prestación de servicios de diferente índole para atender la demanda de los visitantes que van a la ciudad en busca de esparcimiento y tranquilidad en los fines de semana y periodos de vacaciones.

El crecimiento de Paipa igualmente se ha visto orientado por el desarrollo del fenómeno de segunda residencia, pues hay turistas que aprovechan las condiciones naturales como la belleza paisajística, la tranquilidad, la seguridad, así como por la amabilidad de sus gentes que en conjunto con las actividades socioculturales son consideradas como elementos propicios para establecer casas, fincas y cabañas de descanso. Además, la doble calzada facilita el desplazamiento en un tiempo más corto desde ciudades como Bogotá y Tunja permitiendo a la gente viajar los fines de semana sin mayor obstáculo para descansar del ritmo de vida acelerado presente en las grandes urbes. La ciudad en los próximos años presentará un crecimiento mayor en razón al desarrollo y potenciación de las ventajas comparativas y competitivas que posee. 


\section{Literatura citada}

Borja, J. (1997). Local y global. La gestión de las ciudades en la era de la información. Madrid, España: Taurus.

Camargo, G. (1997). Orígenes y florecimiento de Paipa. Bogotá: Sociedad Geográfica de Colombia.

Capel, H. (2002). La morfología de las ciudades. Barcelona: De Serval.

Concejo Municipal de Paipa. (2000). Acuerdo 030 de 2000, por medio del cual se adopta el plan de ordenamiento territorial del municipio. Recuperado en marzo de 2011, de: http://www.paipa boyaca.gov.co/planeacion.shtml?apc $=$ plxx $\sim 1 \sim \mathrm{x}=1362999$

Correa, R. (1938). Guía histórico-geográfica de los 126 municipios de Boyacá. Tunja: Imprenta del Departamento.

Chueca, F. (2000). Breve historia del urbanismo. Madrid: Alianza. Recuperado el 25 de mayo de 2011, de http://libros-revistas-derecho.vlex.es/vid/chueca-goitia-brevehistoria-urbanismo-131249

Harvey, D. (1979). Urbanismo y desigualdad social. Madrid: Siglo XXI.

Harvey, D. (1990). The condition of posmodernity: an enquiry into origins of cultural change. Oxford, Inglaterra: Basil Blackwell. Recuperado el 20 de noviembre de 2010, de http://es.scribd.com/doc/57766251/David Harvey La LCondicion $\sim$ de la posmodernidad

Hernández, G. (1990). De los chibchas a la colonia y la república -del clan a la encomienda y al latifundio en Colombia. Bogotá: Paraninfo.

Mojica, J. (1946). Relación de visitas coloniales. Tunja: Publicaciones de la Academia Boyacense de Historia.

Moncayo, V. (1990). Espacialidad y estado formas y reformas. Bogotá: Universidad Nacional de Colombia.

Pinto, D., Arce, A. \& Gómez, E. (1998). Proceso de urbanización en Colombia. Análisis geográficos, 15, 249- 257.

Portes, A. \& Dore, C. (1996). Ciudades del Caribe en el umbral del nuevo siglo. Venezuela: FLACSO y Nueva Sociedad.

Ramírez, E. (1999). Colombia. Su infraestructura y desarrollo nacional. Recuperado el 25 de mayo de 2011, de www.sogeocol.edu.co

Rincón, M. (2009). Procesos de transformación urbana: el caso de Tunja 1900-2005. Trabajo de grado. UPTC-IGAC, Tunja, Colombia.

Vinuesa, J. (1991). Los procesos de urbanización. España: Síntesis.

Vilagrasa, J. (2011). Ciudades medias en España. Recuperado el 30 de marzo de 2011, de http://es.scribd.com/doc/57502273/Ciudades-arquitectura-y-espacio-urbanoHoracio-Capel

Zarate, M. (1991). El espacio interior de la ciudad. España: Síntesis.

Recepción: 08 de agosto de 2011

Evaluación: 30 de agosto de 2011

Aprobación: 09 de septiembre de 2011

$150 \quad$ Wilson Hernando Rojas Espinel 